\title{
Factors Affecting Public Procurement Performance in Case of Wollega University
}

\author{
Adissu Ketemaw (MA) \\ Wollega University Department Of Logistics And Supply Chain Management, PO box 334
}

\begin{abstract}
The purpose of the study was to assess factors affecting public procurement performance in case study of Wollega University. Specifically, the study examine the variables supplier management, staff competency and inventory management that affect the performance of public procurement. The study was used an explanatory design of research. The study employed stratified with simple random sampling technique to select the respondents. The sample size of the study is 276 respondents from academic and administrative staffs who currently working at Wollega University. Questionnaire and interview as a data collection instrument were used accordingly, The collected data was statistically analyzed by using descriptive statistics, and inferential statics was developed to identify the significant effect of independent variable on dependent variable. Findings indicate that supplier Management followed by inventory management and staff competency are the major factors that affect public procurement and they have a significant positive effect on procurement performance. Finally the study recommends that, chooses suppliers with who have the capacity to deliver, and building truths' relationship with them, improve their store management system by assigning qualified staff and applying a collective effort on developing continuous training programs to perform the effectiveness of procurement practice in the institution.

Keywords: Procurement Performance, supplier management, staff competency and inventory management

DOI: $10.7176 / \mathrm{EJBM} / 12-34-04$
\end{abstract}

Publication date: December $31^{\text {st }} 2020$

\section{INTRODUCTION}

Public procurement means procurement by a public body using public fund. Because of public procurement is run by public money that serves the public interest, procurement officers required to purchase from the firm that offers the best value for money [1].

Performance has been described as the degree of achievement of certain effort or under taking. It relates to the prescribed goals or objectives which form the project parameters. And also Procurement performance covers a number of quality and quantity-enhancing benchmarks, which narrows down transaction costs, time spent, and the quality and quantity of goods delivered. Based on their analysis on the performance of public procurement officers, procurement performance entails high returns on investment, reduced transactional costs, faster delivery of services and supplies, delivery of high quality purchases, and streamlined supply chains [2].

In today's competitive world procurement function become very critical task for every organizations in the world whether they are public or private organizations procurement function is must and thus procurement function effectiveness makes the organization effective and profitable. But, this procurement function faces some challenges most of the time common challenge such as, ensuring efficiency, accountability and transparency, poor quality and delivery delay [3].

In many African countries, public procurement accounts for a substantial part official expenditures, making sound procurement methods central not only for sound public financial management but also for inclusive growth. Effective implementation of procurement practices and procurement policies are critical for good public financial management and effective budget implementation [4].

To facilitate public operations governments often allot the major share of the state budget on procurement. As per the Organization for Social and Economic Development report [5] on the average developing countries public procurement accounts for up to13\% of gross domestic product (GDP). According to Public procurement and property administration agency [6] manual Our country Ethiopia also spends up to15 percent gross demotic product (GDP) and more than 60 percent of public expenditures for procurement of goods and services. This implies that a large amount of money spent by the government every year to procure goods, services and works. This huge budget allocation makes procurement as a heart of government operations.

Purchasing contributes to the firm's efficiency and effectiveness in many ways. First, it helps to determine a firm's cost structure through negotiations with suppliers. Reducing the investment in inventory and improving the quality of incoming parts and components through its vendor selection and supplier development policies [1]

The most prevalent factors in the public procurement process are the selection of the most suitable procurement methods, with appropriate justifications, despite government efforts for improvement; it is still marred by shoddy works, poor quality goods and services. Supplier complain about poor service delivery, quality of procured product, accountability and transparency Benefits deriving from improved procurement performance are dependent on systems and staff [7]. 
This study mainly focuses on factors affecting public procurement performance in Wollega University. The main reason to select this topic is the problems shown in the institution related to spastic factors like inventory management, supplier management and staff competency that affect on procurement performance the institution as the annual report of Wollega University procurement and inventory management office (2017\&2018 E.C.). Therefore This study was more focused and tried to find out the weak link of the public procurement practice which resulted from inventory and supplier management as well as staff competency, effect on procurement performance of quality of procured product and delivery time, which can then be taken up by management to make the required decisions for improving institutional performance.

\section{REVIEW LITERATURE}

This chapter gives an extensive review of the available theoretical, empirical literature and conceptual review and also the concept and definition of variables to the problem being investigated, on factors affecting public procurement performance.

Through the analysis on the related literatures of the theoretical, empirical and legal framework discussions the researcher could understand and show the prevalent gap between theoretical discussions in procurement and what the practical aspect in public procurement looks like. The constructs and relationships between the research variables are illustrated in the following figure.

Independent Variables

\section{Dependent Variable}

\section{Supplier management \\ - Sourcing \\ - Supplier selection \\ - Supplier performance \\ - Supplier relationship}

Staff Competency

- Relevance of skills

- Experience

- Employee training

Inventory management

- Availability of product

- Cost of inventory

- $\quad$ Store management process

Figure 2.4.1 Conceptual Frame work Source: researcher developed for the study, 2017

\section{RESEARCH METHODLOGY}

\subsection{Research Design}

The study was adopted explanatory types of research design. The reason for using this type of research design, as such the research design appropriates for identify any causal links between the factors or variables that affect to the performance of procurement practice at Wollega University. To meet the research objectives properly, both qualitative and quantitative approaches were used.

\subsection{Sample Size Determination and Sapling Technique}

The researcher implied yemanes (1967) sample size determination formula which was as follow,

$$
\mathrm{n}=\frac{\mathrm{N}}{1+\mathrm{N}(\mathrm{e})^{2}}
$$

So, by using this formula 334 respondents were constituted from the total population of 2008 which were academic and supportive staff of Wollega University in Nekemte compass.

In order to get the right data from the right respondent through questionnaire the researcher was decided to use stratified sampling. The population is stratified in to groups depending their department two strata was adopted which ware academic and supportive staff. 
Table 3.1 Target Population and Sample of the Study

\begin{tabular}{|l|l|l|l|}
\hline No. & Staff & Population & Sample \\
\hline $\mathbf{1 .}$ & Academic & $\mathbf{7 6 3}$ & $\mathbf{3 3 4} * \mathbf{7 6 3} / \mathbf{2 0 0 8}=\mathbf{1 2 7}$ \\
\hline $\mathbf{2 .}$ & Supportive & $\mathbf{1 2 4 5}$ & $\mathbf{3 3 4} * \mathbf{1 2 4 5} / \mathbf{2 0 0 8}=\mathbf{2 0 7}$ \\
\hline & Total & $\mathbf{2 0 0 8}$ & $\mathbf{3 3 4}$ \\
\hline
\end{tabular}

Source Wollega University human resource management (WU HRM)

The two strata of academic and supportive staff have different stratum under each strata based on their college and department respectively. This study stratified and simple random sampling technique were adapted because the target population for the study was large and for the need of avoiding sampling error, as well as to get an opportunity to investigate an intensive problem of the study.

\subsection{Source of Data and Data Collection Techniques}

The study was used both primary and secondary types of data. Primary data was collected from the respondent of employees who are working at Wollega University academic and supportive staff. As far as the secondary data concerned the institution report of 2017 and 2018 E.C to support on the procurement performance in the university and also the data was collected through the review of both empirical and theoretical literature sourced from purchasing documents; and federal government purchasing manual books, journals and internet on public procurement practices. In line with the objective of the study, the researcher was developed close-ended and openended questionnaires. The questionnaires was self-administer to a total 334 respondents.

\subsection{Data Analysis Method}

The study was employed both Descriptive and inferential statics method of data analysis. Descriptive statistical method was applied to analyze the quantitative close-ended questions data by using the SPSS computer soft ware through calculating the percentages, mean and frequency. SPSS is considered appropriate since it allows the researcher to follow a clear set of quantitative data analysis procedures that leads to increased data validity and reliability. For the purpose of inferential statistics analyzing to measure the effect of inventory management, supplier management and staff competency on public procurement performance, multiple leaner regressions was employed. Qualitative data draw from open-ended question of the questionnaire and interview guide was analyzed through summary.

\section{DATA PRESENTATION AND ANALYSIS}

\subsection{Reliability Test}

The Cronbach's Alpha reliability test of variable item result from 32 was present in the following table below.

Table 4.1 Reliability Statistics

\begin{tabular}{|c|c|c|}
\hline Variables & Number of items & Cronbach's alpha \\
\hline Supplier management & 6 & 0.762 \\
\hline Staff competency & 6 & 0.747 \\
\hline Inventory management & 5 & 0.793 \\
\hline Procurement performance & 5 & 0.758 \\
\hline Total result & 22 & 0.812 \\
\hline
\end{tabular}

If the reliability test value is greater than 0.7 the scale deemed to be a reliable measure of fore examining the sample. As see from the above table the Cronbach's Alpha coefficient for all variables are more than 0.7.

\subsection{Response Rate}

The study population consisted of 334 respondents. A total 334 Questionnaires were distributed to those respondents. Questionnaires were self-administered to supportive and academic staff of Wollega University. 276 quaternaries were completely filled and returned. The remaining 58questionnaires were not collected due to refusal to give response for the questionnaires. By this reason a response rate can be $82.6 \%$. The response rate of academic and supportive staff was discussed in table below.

Table: 4.2 Response Rate

\begin{tabular}{|l|l|c|c|c|}
\hline No. & Sample unit & $\begin{array}{c}\text { Distributed } \\
\text { questionnaire }\end{array}$ & $\begin{array}{c}\text { Collected } \\
\text { questionnaire }\end{array}$ & Response rate (\%) \\
\hline 1 & Academic staff & $\mathbf{1 2 7}$ & $\mathbf{1 1 1}$ & $\mathbf{8 7 . 4}$ \\
\hline 2 & Supportive staff & $\mathbf{2 0 7}$ & $\mathbf{1 6 5}$ & $\mathbf{7 9 . 7}$ \\
\hline & Total & 334 & 276 & 82.6 \\
\hline
\end{tabular}




\subsection{Demographic Data of the Respondent}

The general characteristics and demographic data of the respondent were discussed as follow.

\subsubsection{Gender Characteristics of the Respondents}

Table 4.2 Gender characteristics descriptive Statistics of the respondent

\begin{tabular}{|l|l|r|r|}
\hline \multicolumn{2}{|l|}{ Gender } & Frequency & Percent \\
\hline \multirow{2}{*}{2} & Male & 161 & 58.3 \\
\cline { 2 - 5 } & female & 115 & 41.7 \\
\cline { 2 - 5 } & Total & 276 & 100.0 \\
\hline
\end{tabular}

The above table shows that $58.3 \%$ of the respondents were males and $41.7 \%$ were female. This may show that there were still low levels of employment of females in the institution gender may necessary for the study to get a balanced picture of the respondents' views about public procurement performance in the institution.

\subsubsection{Highest level of education}

Details about the education levels of respondents were obtained and the results were presented in the figure 3below.

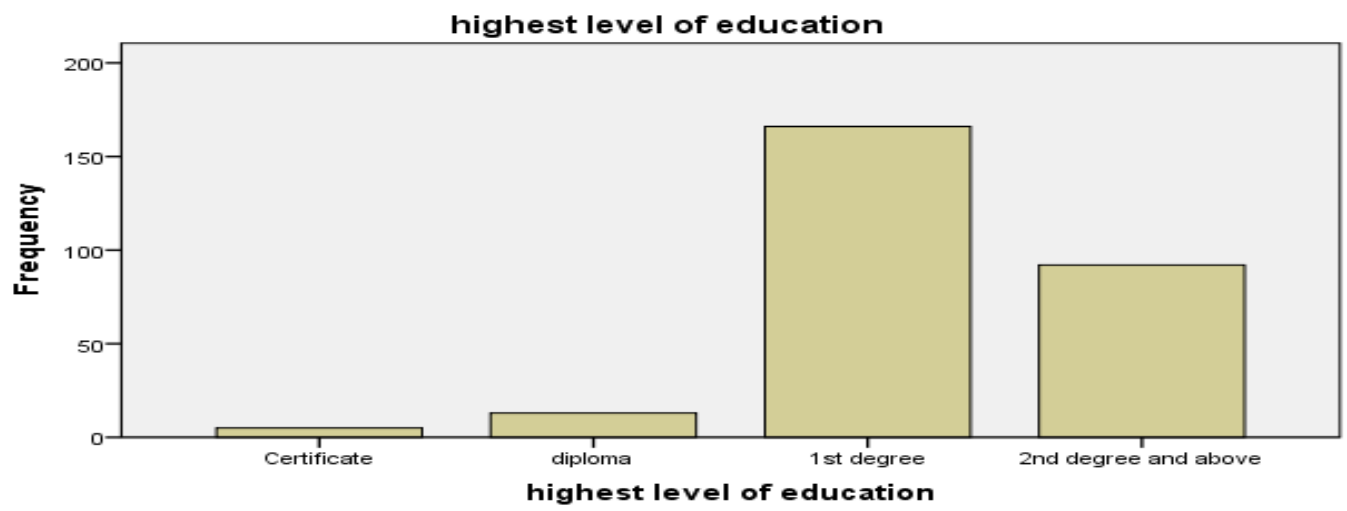

Figure 4.1 educational levels of respondents

As the above figure shows that majority of respondents are first degree holders followed by second degree, diplomas, and certificates of $60.1 \%, 33.3 \%, 4.7 \%$ and $1.8 \%$ respectively. This indicates that the respondents are adequately qualified persons to manage the operations and to know the problem of the study.

\subsubsection{Working Experience}

The study had investigated the work experience of employees in the institution and the findings were presented in the table below.

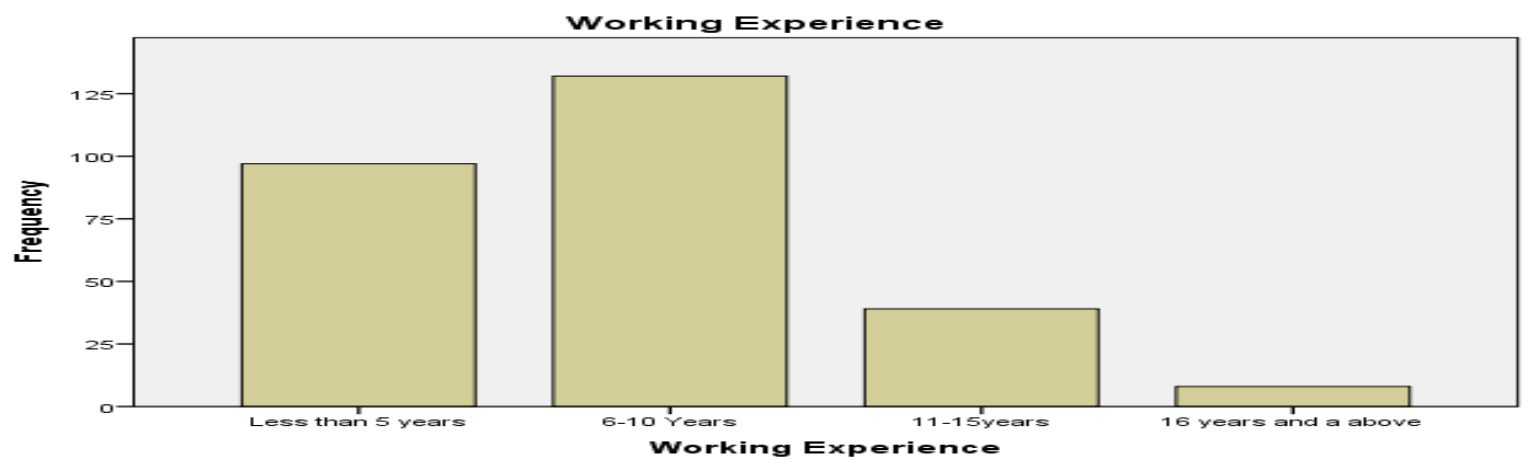

Fig 4.2 Working experience of the respondent

As it summarized in the above table $35.1 \%$ of the respondents have less than 5 years of work experience, $47.8 \%$ have $6-10$ years of experience, $14.1 \%$ of the respondents have $11-15$ years of working experience and $2.9 \%$ have16 years and above work experience. Generally, they had enough experience in the institution. Therefore, they were appreciating the essential of the study and the respondents had a reasonable experience in their job which enables them to evaluate the procurement performance in the institution.

\subsection{Descriptive statistics of the study variable}

For this analysis the study used mean and percentile. Respondents were asked to rate the research questionnaires on factors affecting public procurement performance in the institution on a five-point likert scale ranging from 1 being strongly disagree to 5 strongly agree. The mean statistical value approaching were based on the following assumptions: if the mean value is between ( 0 to 1.5$)$ this implies the respondents strongly disagreed, if the mean 
value is between ( 1.50 to 2.50$)$ it indicates the respondents disagreed, the mean value between (2.50 to 3.50$)$ indicates the respondents were neutral, the mean value between ( 3.50 to 4.50$)$ implies the respondents agreed and a mean value 4.50 and above shows the respondents strongly agreed [8].

\subsubsection{Descriptive Statistics of supplier management}

Table 4.5 Descriptive Statistics of supplier management

\begin{tabular}{|c|c|c|c|c|c|c|c|}
\hline \multirow[t]{2}{*}{ No. Items } & \multirow[t]{2}{*}{$\mathrm{N}$} & \multicolumn{5}{|c|}{ Percent $100 \%$} & \multirow[t]{2}{*}{ Mean } \\
\hline & & SDA & DA & $\mathrm{N}$ & $\mathrm{AG}$ & $\mathrm{AG}$ & \\
\hline $\begin{array}{l}\text { 1. The procurement department offer the requested } \\
\text { item From the Right Source }\end{array}$ & 276 & 24.6 & 62.3 & 5.4 & 2.5 & 5.1 & 2.01 \\
\hline $\begin{array}{l}\text { 2. The institution has adequate suppliers of } \\
\text { various products. }\end{array}$ & 276 & 14.9 & 65.2 & 7.6 & 8.0 & 4.3 & 2.22 \\
\hline $\begin{array}{l}\text { 3. The institution follow appropriate supplier } \\
\text { selection criteria }\end{array}$ & 276 & 2.2 & 11.6 & 11.6 & 53.3 & 21.4 & 4.0 \\
\hline $\begin{array}{l}\text { 4. The institution has appropriate supplier } \\
\text { performance measurement system. }\end{array}$ & 276 & 22.1 & 49.3 & 21.0 & 5.4 & 2.2 & 2.16 \\
\hline $\begin{array}{l}\text { 5. The institution suppliers delivered required } \\
\text { quantity of material with right quality. }\end{array}$ & 276 & 26.1 & 54.7 & 11.2 & 5.1 & 2.9 & 2.04 \\
\hline $\begin{array}{l}\text { 6. The institution has good relationship with } \\
\text { their suppliers }\end{array}$ & 276 & 16.7 & 65.6 & 9.4 & 5.1 & 3.3 & 2.13 \\
\hline
\end{tabular}

As illustrated in the above, table $62.3 \%$ of respondents with a mean of (2.1) are disagreed on the procurement department offer the requested item From the Right Source. The remaining $24.6 \% 5.4 \% 2.5 \%$ and $5.1 \%$ of the respondents are strongly disagreed, neutral, agreed and strongly agreed to the given statement respectively. From this result, we can conclude that the procurement department did not offer the requested item from the right source The respondents also disagreed on the institution has adequate suppliers of various products $65.2 \%(\mathrm{mean}=2.22)$. The other $14.9 \%$ strongly disagreed $7.6 \%$ neutral, $8.0 \%$ agreed and $4.3 \%$ strongly agreed to the given statement. From it is possible to conclude that there are problems of availability of vendors for different materials that can purchase by the institution as the user required

$53.3 \%$ of respondents with a mean of (4.2) are agreed on the institution follow proper supplier selection criteria. The other $21.4 \%, 11.6 \%, 11.6 \%$ and $2.2 \%$ of the respondents are strongly agreed, neutral, disagreed and strongly disagreed with the given statement respectively. Therefore it is possible to conclude that the institution has good supplier selection criteria based on the user need to offer the requested item from the right source. $49.3 \%$ of respondents with a mean of (2.16) are disagreed on the institution has an appropriate supplier performance measurement system. The other $22.1 \%, 21.0 \%, 5.4 \%$ and $2.2 \%$ of the respondents are strongly disagreed, neutral, agreed and strongly agreed to the given statement respectively. This implies that there is no good supplier measurement system. A majority of respondents are disagreed on the institution suppliers delivered required a quantity of material with right quality $54.7 \%$ (mean of 2.05 ). The other $26.1 \%$ strongly disagree $11.2 \%$ neutral, $5.1 \%$ agree and $2.9 \%$ strongly agreed to the given item. From this, it is possible to conclude that there is a problem of product quality with requested quantity offered by their suppliers Finally, the respondent raised on the item, the institution has good relationship with their suppliers $65.6 \%$ (mean of 2.13) respondents are disagreed. The remaining respondents are in the order $16.7 \%, 9.4 \%, 5.1 \%$ and 3.3\% strongly disagreed, neutral, agreed and strongly agreed to the given statement. This implies the institution had not good relationship with their suppliers. On the other hand from the interview, interviewees respond that the department has a good relationship with their loyal suppliers.

From this study, it was possible to identify that challenge of supplier management practice which are offer the requested item From the Right Source, adequate supplier, relationship with their suppliers, delivered required quality and quantity of material with right time are not excellent to perform the procurement practice in the institution even the institution has effective supplier selection criteria. And also on the open deeded question the respondent asked to answer the question the challenge of supplier management on procurement performance most respondents wrote that lack of available supplier in the local market, lack of honesty supplier, time wasting of delivered their product high price agreement per item and suppliers delivered low quality product, punctuality and reliability problem are the most challenges of supplier management in the institution.

\subsubsection{Descriptive Statistics of staff competency}

The Descriptive Statistics of staff competency was evaluated interns of employees profession, qualification, experience recruitment and training. Detail Descriptive Statistics of staff competency was presented at the table below. 
Table 4.6 Descriptive Statistics of staff competency

\begin{tabular}{|l|c|c|c|c|c|c|c|}
\hline \multirow{2}{*}{ No. Items } & $\mathrm{N}$ & \multicolumn{2}{|c|}{ percent $100 \%$} & Mean \\
\cline { 2 - 8 } & & SDA & DA & N & AG & SAG & \\
\hline $\begin{array}{l}\text { 1. } \\
\text { Procurement Staffs have recognized professional } \\
\text { procurement qualifications }\end{array}$ & 276 & 18.5 & 52.2 & 12.7 & 8.3 & 8.3 & 2.36 \\
\hline $\begin{array}{l}\text { The organization recruits competent staff to handle } \\
\text { the procurement function }\end{array}$ & 276 & 3.3 & 23.2 & 10.5 & 35.5 & 25.5 & 3.61 \\
\hline $\begin{array}{l}\text { 3. } \\
\text { Procurement staffs have a skill to understand the } \\
\text { need of users department }\end{array}$ & 276 & 30.1 & 45.3 & 15.9 & 8.0 & 0.7 & 2.04 \\
\hline $\begin{array}{l}\text { 4. } \\
\text { Procurement staffs have good experience to } \\
\text { negotiate with suppliers }\end{array}$ & 276 & 12.4 & 62.0 & 10.1 & 3.6 & 6.9 & 2.21 \\
\hline $\begin{array}{l}\text { The institution has appropriate periodic employee } \\
\text { training on procurement practices }\end{array}$ & 276 & 23.2 & 48.9 & 9.1 & 12.7 & 6.2 & 2.18 \\
\hline $\begin{array}{l}\text { There is a smooth workflow between procurement } \\
\text { staff employees and user department }\end{array}$ & 276 & 17.8 & 61.6 & 9.4 & 7.6 & 3.6 & 2.30 \\
\hline
\end{tabular}

The table illustrates that majority respondents are disagreed on Procurement Staffs have recognized professional procurement qualifications $52.2 \%(\mathrm{a}$ mean $=3.72$ ). The remaining $18.5 \%, 12.7 \%, 8.3 \%$, and $8.3 \%$ respondents are strongly disagreed, neutral, agreed and disagreed respectively. This implies that most of the respondent disagreed that there is no recognized procurement professional qualification in the institution. on the other hand on the interview equation they respond that there are procurement experts and qualified employees in the department their profession are a related field from different, business area specialties, consultancy and IT experts but not pure procurement profession. The respondents also greed on the institution recruits competent staff to handle the procurement function $35 . \%$ (mean $=3.61)$. The remaining respondents are $25.5 \%$ strongly agreed, $10.5 \%$ neutral $23.2 \%$ disagreed and $3.3 \%$ strongly disagree to the given statement. From this we can conclude that the institution recruits competent staff and they handle the procurement function in a good manner.

$5.3 \%$ of respondents with (a mean $=2.02$ ) are disagreed on Procurement staffs have a skill to understand the need of users department. The other $30.1 \%, 15.9 \%, 8.0 \%$ and $0.7 \%$ of the respondents are strongly disagreed, neutral, agreed and strongly agreed to the given statement respectively. Therefore it is possible conclude that in the institution procurement staffs have not good skill to understand and to identify users need.

$62.0 \%$ of respondents with (mean $=2.21)$ are disagreed on Procurement staffs have good experience to negotiate with suppliers. The other $12.4 \%, 10.1 \%, 3.6 \%$ and $6.9 \%$ of the respondents are strongly disagreed, neutral, agreed and strongly agreed to the given statement respectively. This inform that there are low experience employees in the procurement staff to identify and negotiate the available suppliers The respondents also disagreed on the institution has appropriate periodic employee training on procurement practices $48.9 \%($ mean $=2.18)$. The other $23.2 \%$ strongly disagree $9.1 \%$ neutral, $12.7 \%$ agreed and $6.2 \%$ strongly agreed to the given item. From this it is possible conclude that there is no proper employee training in the institution to improve their experience on procurement profession. training is a key element for improved organizational performance through the increasing level of individual competences which means that training would help employees to master knowledge, skills, behaviors, sense of self worth and confidence upon which they are able to perform efficiently to improve on the performance of the organization. But in the intuition of there is no appropriate periodic employee training Most respondents were disagreed on There is a smooth workflow between procurement staff employees and user department by $61.6 \%$ (mean $=2.3)$. The other respondent strongly disagreed $(17.8 \%)$, neutral $(9.6 \%)$, agreed $(7.4 \%)$ and strongly agreed $(3.6 \%)$. This means that the store management system were not flexible depended on the user requested time, quantity and quality.

From this it is possible conclude that the institution in terms of staff competency most respondents are disagreed on Procurement staffs have good experience to negotiate with suppliers, periodic employee training on procurement practices and a smooth workflow between procurement staff employees and user department not sufficient to handle procurement function, the institution has not a recognized professional procurement qualifications. 


\subsubsection{Descriptive statics of inventory management}

Table 4.6 Descriptive statics of inventory management

\begin{tabular}{|c|c|c|c|c|l|l|l|}
\hline \multirow{2}{*}{ No. Items } & $\mathrm{N}$ & \multicolumn{2}{|c|}{ percent $10 \%$} & Mean \\
\cline { 2 - 8 } & & SDA & DA & $\mathrm{N}$ & AG & SAG & \\
\hline $\begin{array}{l}\text { There is high speed for delivery of material } \\
\text { in the institution }\end{array}$ & 276 & 30.4 & 52.9 & 9.1 & 5.8 & 1.8 & 1.96 \\
\hline $\begin{array}{l}\text { 2. } \\
\text { There is flexible store management system in } \\
\text { the institution. }\end{array}$ & 276 & 18.1 & 67.4 & 10.1 & 2.9 & 1.4 & 2.02 \\
\hline $\begin{array}{l}\text { The institution has consistent availability of } \\
\text { materials in the store }\end{array}$ & 276 & 17.8 & 59. & 11.6 & 8.0 & 3.6 & 2.21 \\
\hline $\begin{array}{l}\text { The department has appropriate and periodic } \\
\text { review of inventory }\end{array}$ & 276 & 25.7 & 56.2 & 10.1 & 4.7 & 3.3 & 2.04 \\
\hline \hline $\begin{array}{l}\text { The institution has effective storage } \\
\text { management to minimize wastage of } \\
\text { materials }\end{array}$ & 276 & 22.1 & 54.0 & 17.4 & 4.3 & 2.2 & 2.11 \\
\hline
\end{tabular}

The above table shows that majority respondents are disagreed on There is high speed for delivery of material in the institution by $52.9 \%$ (mean=1.96) and the remaining respondents are strongly disagreed, neutral, agreed and strongly agreed by $30.4 \%, 9.1 \%, 5.8 \%, 1.8 \%$ respectively. This implies that there is no speed of deliveries of user requested material from the store. The respondents also disagreed on The institution has consistent availability of materials in the store $59 \%$ (mean $=2.21$ ) and they are strongly disagreed, neutral, agreed and strongly agreed by $17.8 \%, 11.6 \%, 8.0 \%$ and $3.6 \%$ respectively. From this, it is possible to conclude that there is a problem of material availability with requested quantity with consistently. This means that there is a lack of consistency on the availability of material in the store.

Most respondents $56.2 \%$ (mean $=2.04$ ) disagreed on the department has an appropriate and periodic review of inventory. The other $25.7 \%, 10.1 \%, 4.7 \%$ and $3.3 \%$ of the respondents are strongly disagreed, neutral agreed and strongly agreed respectively to the given item. From this, it is possible concluded that the institution has not good and appropriate periodic review of inventories. The respondents also disagreed on the institution has effective storage management to minimize wastage of materials 54.0 . \% (mean $=2.11$ ). The remaining $22.1 \%$ strongly disagreed, $10.517 .4 \%$ neutral $4.3 \%$ agreed and $2.2 \%$ strongly agreed to the given statement. From this, we can conclude that the institution has not effective storage management and there is wastage of materials.

This implies that the institution in terms of inventory management which are speed for delivery of material, flexible warehouse management system, consistent availability of materials and effective storage management is not sufficient to handle procurement practice. And also on the open deeded question the respondent asked to answer the question the challenge of inventory management on procurement performance most respondents wrote that lack of material handling in the store, shortage of material, no warehouse in the institution, lack of sufficient storage for materials.

\subsubsection{Descriptive statics of public procurement performance}

The Descriptive Statistics of procurement performance was evaluated interns 5 Rs which are right quality right quantity, right time and right source. Detail Descriptive Statistics of procurement performance was presented at the table below.

Table 4.7 descriptive statics of procurement performance

\begin{tabular}{|c|c|c|c|c|c|c|c|}
\hline & $\mathrm{N}$ & Perce & nt $\%$ & & & & Mean \\
\hline NO. Items & & SDA & $\mathrm{DA}$ & $\mathrm{N}$ & $\mathrm{AG}$ & SA & \\
\hline $\begin{array}{l}\text { 1. The procurement department deliver the requested item With } \\
\text { Right Quality. }\end{array}$ & 276 & 29.3 & 49.6 & 10.1 & 6.9 & 4.0 & 2.07 \\
\hline $\begin{array}{l}\text { 2. The procurement staff delivers the requested item At Right } \\
\text { Time. }\end{array}$ & 276 & 25.7 & 39.9 & 15.2 & 7.6 & 11.6 & 2.39 \\
\hline $\begin{array}{l}\text { 3. The procurement department delivers the requested item } \\
\text { with Right Quantity. }\end{array}$ & 276 & 27.2 & 46.0 & 17.0 & 7.6 & 2.2 & 2.12 \\
\hline $\begin{array}{l}\text { 4. There is appropriate specification based on user's product } \\
\text { requirements. }\end{array}$ & 276 & 15.6 & 61.2 & 10.9 & 5.8 & 6.5 & 2.26 \\
\hline $\begin{array}{l}\text { 5. Procurement process takes short time to deliver an item you } \\
\text { requested. }\end{array}$ & 276 & 22.5 & 60.5 & 9.1 & 4.3 & 3.6 & 2.06 \\
\hline
\end{tabular}

As illustrated in the table above, $49.6 \%$ respondents with (mean of 2.07) are disagreed on procurement department deliver the requested item With Right Quality. The other 29. 3\% $10.1 \% 6.9 \%$ and $4.0 \%$ of the respondents are strongly disagreed, neutral, agreed and strongly agreed to the given statement respectively. The respondents also disagreed on procurement staff deliver the requested item At Right Time 39.9\% (mean =2.39). 
The other $25.7 \%, 15.2 \%, 7.6 \%$ and $11.6 \%$ Strongly disagree, neutral, agree and strongly agreed respectively to the given statement. $46.0 \%$ of respondents with $($ mean $=2.12)$ are disagreed on The procurement department deliver the requested item with Right Quantity .The other $27.2 \%, 17.0 \%, 7.6 \%$ and $2.2 \%$ of the respondents Strongly disagreed, neutral, agreed and strongly agreed respectively to the given statement. 61.2 respondents with (a mean $=4.2$ ) disagreed on There is appropriate specification based on user's product requirements. The other $15.6 \%, 10.9 \%, 5.8 \%$ and $6.5 \%$ of the respondents strongly disagreed, neutral, agreed and strongly agreed to the given statement respectively. Finally the respondent raised on the Procurement process takes short time to deliver an item you requested $60.5 \%$ (mean $=2.05$ ) were disagreed. The other respondent the $22.5 \%$ strongly disagreed $9.1 \%$ neutral, $4.3 \%$ agreed and $2.9 \%$ strongly agreed to the given item.

From this study, it was possible to identify that there are problems on procurement performance of the institution like deliver the requested item With Right Quality, right quantity within right time and a lack of proper specification based on user's product requirements and Procurement process takes a long time to deliver an item as user requested.

\subsection{Regression analysis of study}

Multiple regressions were performed between procurement performance as the dependent variable and supplier management, staff competency and inventory management as independent variables.

\subsubsection{Model Summary}

Table 4.8 Regression model summery

\begin{tabular}{|l|l|l|l|l|}
\hline Model & R & R Square & Adjusted R Square & Std. Error of the Estimate \\
\hline 1 & $\mathbf{0 . 8 2 3}$ & $\mathbf{0 . 6 7 7}$ & $\mathbf{0 . 6 7 3}$ & $\mathbf{0 . 3 1 2 6 6}$ \\
\hline \multicolumn{2}{|l}{ a. Predictors: (Constant), Inventory management, staff competency, supplier management } \\
\hline
\end{tabular}

The result of multiple regressions shows that regression model of procurement performance coefficient of determination R Square was 0.677 and $\mathrm{R}$ was 0.823 . The coefficient of determination R Square indicated that $67.7 \%$ of the variation on procurement performance can be explained by the set of independent variables, namely supplier management, staff competency and inventory management. The remaining $32.3 \%$ of variation of procurement performance can be explained by other variables not included in this model. This shows that the model has a good fit since the value is above $50 \%$. On the other hand, adjusted R-squared provides an adjustment to the R-squared statistic such that an independent variable that has a correlation to dependent variable increases adjusted R-squared and any variable without a strong correlation will make adjusted R-squared decrease.

\subsubsection{ANOVA}

Table 4.9 analysis of variance (ANOVA)

\begin{tabular}{|c|c|c|c|c|c|c|}
\hline \multicolumn{2}{|c|}{ Model } & Sum of Squares & Df & Mean Square & $\mathbf{F}$ & Sig. \\
\hline \multirow[t]{3}{*}{1} & Regression & 55.664 & 3 & 18.555 & 189.802 & $0.000^{b}$ \\
\hline & Residual & 26.590 & 272 & .098 & & \\
\hline & Total & 82.254 & 275 & & & \\
\hline \multicolumn{7}{|c|}{ a. Dependent Variable: Procurement performance } \\
\hline
\end{tabular}

In the ANOVA table the $\mathrm{F}$ value of 189.802 which is significant with $\mathrm{p} .000$. This informs that the three independent variables taken together as a set are significantly related to the dependent variable. The $\mathrm{F}$ critical at 5\% level of significance is 0.098 . Since F calculated 189.802 is greater than the thus show that the model is significant. The value of $\mathrm{F}$ is large enough to conclude that the set coefficients of the independent variables are not jointly equal to zero. This implies that at least one of the independent variables has an effect on the dependent variable.

4.5.3 Coefficient of public procurement performance

Table 4.9 coefficient of the variable

\begin{tabular}{|l|l|l|l|l|l|}
\hline \multirow{2}{*}{ Model } & \multicolumn{2}{|l|}{ Unstandardized Coefficients } & $\begin{array}{l}\text { Standardized } \\
\text { Coefficients }\end{array}$ & $\mathrm{t}$ & \multirow{2}{*}{ Sig. } \\
\cline { 2 - 6 } & $\mathrm{B}$ & Std. Error & Beta & -.179 & .858 \\
\hline (Constant) & -.021 & .119 & & 11.898 & .000 \\
Supplier management & .604 & .051 & .573 & 3.886 & .000 \\
staff competency & .155 & .040 & .136 & 5.842 & .000 \\
\hline
\end{tabular}

a. Dependent Variable: Procurement performance

The above table shows the coefficient of dependent variable public procurement performance and all 
independent variable. As beta coefficient show that supplier management had a coefficient of 0.604 which is greater than zero. The t statics is 11.898 which has a p-value of 0.000 which is less than 0.05 implies that the coefficient of supplier management is significant at 0.05 level of significance. This shows that supplier management has a significant positive influence on procurement performance. And also staff competency had a coefficient of 0.155 which is greater than zero. The t statics is 3.886 which has a p-value of 0.000 is less than 0.05 . This means that the staff competency coefficient is significant at 0.05 levels. This shows that staff competency has a significant positive influence on procurement performance. The coefficient of inventory management was0.260which is greater than zero. The $\mathrm{t}$ statistic of this coefficient is 5.842 with a $\mathrm{p}$ value of .000 which is less than 0.05 . This implies that the coefficient of inventory management is significant at 0.05 level. This shows that inventory management has a significant positive effect on procurement performance. The constant term was 0.021. The constant term is the value of the dependent variable when all the independent variables are equal to zero. The constant term has a p-value of 0.858 which is greater than 0.05 . This implies that the constant term is insignificant.

A multiple regression model was used to determine whether independent variables, as symbolized by SM= supplier management, $\mathrm{SC}=$ staff competency, $\mathrm{INM}=$ inventory management, altogether affected the dependent variable $\mathrm{PP}=$ public procurement performance .The Multiple regression models was as follows:

$\mathrm{Y}=\beta 0+\beta 1 \mathrm{X} 1+\beta 2 \mathrm{X} 2+\beta 3 \mathrm{X} 3+\mathrm{e}$

$\mathrm{PP}=-0.021+0.604 \mathrm{SM}+0.155 \mathrm{SC}+0.26 \mathrm{INM}+\mathbf{0} .119$

The regression equation above shows that, by taking all factors into account constant at zero, the public procurement performance will have a value of - 0.021 . And the findings result also show that taking all other independent variables at zero, one unit increase in supplier management would lead to $60.4 \%$ of increase in the procurement performances; one unit increase in staff competency would lead to $15.5 \%$ of procurement performances, one unit increase in inventory management would lead to increase in a $26.0 \%$ increase in procurement performances.

\section{CONCLUSIONS AND RECOMMENDATIONS \\ 5.1 Conclusion}

The study concludes that supplier management has a significant positive influence on procurement performance. It was show as the most important factor that affects procurement performance. The study concludes that staff competency also has a significant positive influence on procurement performance. Even though, Staff competencies in procurement unit affect the efficiency of procurement performance. The institution is not giving sufficient emphasis as can be observed from the finding. And also the study concludes that inventory management has a significant positive influence on procurement performance. It was also the most important factors next to supplier management that affect procurement performance. From the finding the major problems of inventory management practice are Low speed for delivery of material, less flexible store management system, inconsistent availability of materials, Ineffective storage management. Finally, the study concludes that all independent variable such as supplier management, staff competency, and inventory management have significant positive influence on procurement performance. This direct influence leads to reduce procurement performance. The institution's procurement performance is a poor on to deliver the requested item with right Quality, right quantity within right time, a poor specification based on user's product requirements and the Procurement process takes a long time to deliver an item as user requested.

\subsection{Recommendation}

Supplier management is one of the roles of the procurement unit.. Therefore the procurement department is recommended to work on the following Supplier management practice. It is better to strength the process of supplier selection, administration and monitoring of supplier services and products and chooses suppliers with who have the capacity to deliver, this leading to improved procurement performance. The institution, it is better to strength the practice of Assigned qualified staff for purchasing material which can have skills, experience and ability to understand and identify the user need and delivered the requested item. And also the institution is advised to recruit employees most importantly having trained and qualified procurement specialists, who are competent to conduct and manage such procurements, in a professional, timely and cost effective and It is advised to establish effective stores management and material handling system. This helps to reduce wastage of materials. And it is better to improve Inventory control systems, based on different products and accessories which are frequently requested by users as this will reduce delays and work interruptions and also unnecessary order expenses. And also in the department, It is better to have A clear, complete, and accurate functional and detail periodic review inventories this helps to know the required material and prepare efficient procurement plan and reduce wastage of material in the store.' As the study result showed that Wollega University has low procurement performance in terms of five R's of purchasing principles. For that reason the following recommendations were made in order to improve procurement performance in the institution. The institution recommended improving procurement 
performance by having efficient purchasing management that can purchase right quality item, in the right quantity, from the right source, purchased for the right price and delivered at the right time.

\subsection{Suggestion for Further Study}

The study variables were supplier management; staff competency and inventory management. But they were not the only factors that affecting public procurement performance. As per the researcher, there is a need for future to examine other factors that affect procurement performance like availability of vendor's contract and bid management, need identification, procurement planning, quality specification lead time management, budget availability, and accountability and transparency.

\section{REFERENCE}

[1] Hill, L. D. (2001). basic supply chain manegement. New York Washington, D.C. Printed in the United States of America.

[2] Blackburn, J. (2010). Fundamentals of purchasing and inventory control for certifedpharmacy technicians A Knowledge Based Course. United States: J\&D Educational Services.

[3] Amemba. (2015). Challenges Affecting Public Procurement Performance Process in kenya. European Journal of Business and Management, 7 (7).

[4] Kiage, J. O. (2013). Factors Affecting Procurement Performance: A Case of Ministry of Energy. International Journal of Business and Commerce, 3 (1).

[5] OECD. (2015). Public Procurement for Sustainable and Inclusive Growth. OECD.

[6] PPAA, P. (2010). Public Procurement Implimentation Manual. Public Procurement and Property Administration Agency, Adiss Abeba.

[7] Chimwani, B. Iravo, D. M., \& Tirimba, O. (2014). Factors Influencing Procurement Performance In The Kenyan Publicsector. Innovative Space of Scientific Research Journals , 9 (4),

[8] Wanyonyi, S. (2015). Factors Affecting Performance of Procurement function Among Public Technical Training institutions In Kisumu County, Kenya. International Journal of Economics, Commerce and Management, 3 (5). 